\title{
AN EXTENDED CAR-FOLLOWING MODEL CONSIDERING THE INFLUENCE OF BUS
}

\author{
Jinxing Shen, Feng Qiu, Rui Li, Changjiang Zheng
}

Original scientific paper In order to describe car-following behaviour of traffic flow which is composed of buses and passenger cars on freeway, an extended car-following model is proposed for single lane traffic in this paper. The proposed model discriminates four types of car-bus following combination, car-following-bus, busfollowing-bus, bus-following-car and car-following-car. The four combinations are considered in terms of following distance, following speed and following acceleration/deceleration. The proposed methodology is demonstrated using data collected from the combination of microwave radar detector and roadside laser detector on Xuanwu Avenue in the main urban area of Nanjing. Besides, the field data is divided into two data sets, one used for the training of the model, and the other for evaluation purpose. Gazis model and Edie model, the two most extensively used car-following models, are calibrated against the same training data sets and used as a reference benchmark. Finally, the performance of the model, proposed by this paper, was compared with the two classic models based on the evaluation data sets. The results show that buses have different characteristics and manoeuvrability compared with passenger cars. With the influence of buses in the car-following process, it could lead to uneven distribution of traffic flow on the lanes and become the main reason for traffic highway capacity decline. The model, proposed in this paper, is more accurate and stable when predicting acceleration/deceleration of different vehicles during car-following. It has better superiority to describe the car-following behaviours under the influence of bus on freeway.

Keywords: bus; car-following model; model calibration; stimulus-response process; traffic flow

Prošireni model kolone vozila koji uzima u obzir utjecaj autobusa

Izvorni znanstveni članak

Kako bi se opisalo ponašanje prometa kolone vozila, koja se sastoji od autobusa i osobnih automobila na autocesti, u ovom članku je predložen prošireni model kolone vozila za promet u jednoj traci. Predloženi model razlikuje četiri vrste kombinacija kolona automobil-autobus, automobil-nakon-autobusa, autobus-nakon-autobusa, autobus-nakon-automobila i automobil-nakon-automobila. Četiri kombinacije uzimaju u obzir udaljenost, brzinu i ubrzavanje/usporavanje kolone. Predložena metodologija je prikazana uporabom podataka prikupljenih kombinacijom mikrovalnog radarskog detektora i cestovnog laserskog detektora na aveniji Xuanwu u glavnom urbanom području Nanjinga. Osim toga, podaci o terenu podijeljeni su u dva seta podataka, jedan se koristi za uvježbavanje modela, a drugi je za ocjenu. Gazis model i Edie model, dva najčešce korištena modela kolone vozila, kalibrirani su prema istim skupovima podataka za vježbu, a koriste se kao referentna vrijednost. Konačno, izvedba modela, predložena ovim radom, uspoređena je s dva klasična modela na temelju evaluacijskih skupova podataka. Rezultati pokazuju da autobusi imaju različite karakteristike i manevriranost u usporedbi s osobnim automobilima. Uz utjecaj autobusa u procesu kolone vozila, to bi moglo dovesti do nejednake distribucije prometa na trakama i postati glavni razlog za smanjenje kapaciteta prometa autocesta. Model, predložen u ovom radu, precizniji je i stabilniji pri predviđanju ubrzanja/usporavanja različitih vozila tijekom kolone automobila. Nadmoćniji je za opis ponašanja kolone automobil pod utjecajem autobusa na autocesti.

Ključne riječi: autobus; kalibracija modela; model automobilske kolone; protok prometa; postupak stimulacija-reakcija

\section{Introduction}

Car-following models, which describe the processes by which drivers follow each other in the traffic stream, have been the fundamental and pivotal issue in the modern traffic flow theory [1]. If the vehicle does not maintain a proper distance from the leading vehicle during the car-following process, it may result in a traffic collision [2]. Since Pipes et al. firstly put forward the carfollowing model based on safety distance in 1953 [3], many researchers have studied the car-following model from different perspectives. In 1958, Gazis et al. pointed out that the sensibility of vehicle acceleration variation in car-following behavior was related not only to the spacing between the vehicles, but also to the speed of the following vehicle [4]. They proposed a stimulationreaction car-following model on the basis of Chandler Model. Edie et al. thought vehicles are non-interacting under extremely low density of traffic flow and proposed a new model according to Chandler Model [5]. In the Edie Model [6], the sensible of acceleration/deceleration of the following vehicle is related to the speed of themselves. The speed is faster of the following vehicle, the more sensitive the acceleration/deceleration is. On this basis, Sheu [7], Yu [8], Liu [9], Tang [10, 11], Yu [12], Zhu [13], Zheng [14], Saifuzzaman [15], Davoodi [16] calibrated parameters in the basic stimulation-reaction model from different perspectives to optimize the model. The study of these researchers helps the model greatly reflect the characteristic of car-following in actual traffic stream.

But one of the hypotheses of these models is supposed to be homogeneous. They assume the following behaviors will be similar when responding to the same stimulation [17]. In fact, different types of vehicles react variously when following and their behaviors are influenced by vehicle performance in spite of same stimulation [18]. Increasing number and proportion of different vehicles in the traffic stream may result in quite different traffic flow characteristics [19]. Sarvi [20] used the data from congested heterogeneous traffic conditions to investigate car-following behaviors between heavy vehicles and passenger cars. The findings of his research show the complication of acceleration/deceleration of heavy freight vehicles causes larger space and time headways when traffic flow approaches capacity. Besides, heavy freight vehicles intend to keep a stable speed when following and the reaction time of different drivers' changes less obviously [21]. Yang et al. [22] used cellular automation to simulate the car-following behaviors of heavy freight vehicles when following passenger cars, which indicates that car-following behaviors between heavy freight vehicles and passenger cars will exert different impact on traffic capacity if traffic flow state 
changes. In the congested conditions, highway capacity will be improved efficiently if the random combination of car-following behaviors between heavy vehicles and passenger cars is decreased [23]. Li [24] believed the stability of car-following model in heterogeneous traffic stream has something to do with average headways during following, but nothing to do with the standard deviation of headways. Liu et al. extended their modeling and simulated analysis to focus on the importance of composition ratio of heavy freight vehicles and passenger vehicles [25].

Based on the results, heterogeneity of traffic stream should be the key point in the study of car-following model. However, there has been very little research regarding the relationship between passenger vehicles and bus. It is a common phenomenon in mainland China that public transit always appears in the heterogeneous traffic steam especially in the express way, of which the influence should be taken into consideration. More and more serious congestion appears in this developing country, and most of the vehicles on rush hours are public transport and passenger car because heavy freight vehicles are forbidden driving on the expressway during rush hours in accordance with government regulation in this situation. The homogeneous traffic flow models are not able to describe actual traffic flow conditions precisely with the approaching proportion of passenger cars and public transits.

Therefore, the paper has constructed an extended carfollowing model to describe car-following behaviors in the expressway considering the influence of public transit through model calibration by field data. The paper is organized as follows. The construction of the extended car-following model is given in Section 2. In Section 3, the field data were collected and analyzed. The model is fitted and analyzed in Section 4. Finally, concluding remarks and a summary of findings are contained in Section 5.

\section{Model building}

Considering the importance of relative speed and reaction time of drivers, Chandler et al. proposed a line car-following model on the basis of stimulus-response process [3]. Its formulation is

$$
\ddot{x}_{n, t}=\beta_{0} \times\left[\dot{x}_{n-1, t-\Delta t}-\dot{x}_{n, t-\Delta t}\right]
$$

where $\Delta t$ is the driver's response time lag, $\ddot{x}_{n, t}$ is the acceleration/deceleration of vehicle $n, \dot{x}_{n-1, t-\Delta t}$ is the instantaneous speed of vehicle $n-1$ at time $t-\Delta t, \dot{x}_{n, t-\Delta t}$ is the instantaneous speed of vehicle $n$ at time $t-\Delta t$, $\dot{x}_{n-1, t-\Delta t}-\dot{x}_{n, t-\Delta t}$ is the relative speed at time $t-\Delta t$, and $\beta_{0}$ is the sensitivity coefficient of drivers, which is related to the space headway.

In the Chandler model, the relative speeds of two vehicles are assumed to be the stimulation, which can be regarded to be positive or negative or zero. It shows the following vehicle speeds up or down, or just keeps an even speed under the influence of the leading vehicle. Gazis et al. believed following stimulation sensitivity of different vehicles always changes and is not only concerned with space headway but also with instantaneous speed and speed difference [4]. They improved the original car-following model and derived Eq. (2),

$\ddot{x}_{n, t}=\beta_{G 0} \frac{\left[\dot{x}_{n, t-\Delta t}\right]^{\beta_{G 1}}}{\left[x_{n-1, t-\Delta t}-x_{n, t-\Delta t}\right]^{\beta_{G 2}}}\left[\dot{x}_{n-1, t-\Delta t}-\dot{x}_{n, t-\Delta t}\right]$,

where the sensitivity of car-following model is made of $\beta_{G 0}, \beta_{G 1}$ and $\beta_{G 2}$, in which $\beta_{G 0}$ is the sensitivity coefficient of drivers, $\beta_{G 1}$ is the sensitivity coefficient of speed, and $\beta_{G 2}$ is the sensitivity coefficient of space headway.

$\left[x_{n-1, t-\Delta t}-x_{n, t-\Delta t}\right]$ is the space headway between vehicle $n-1$ and vehicle $n$, and other parameters are similar to Eq. (1).

Edie et al. [5] thought the Chandler model cannot give a proper description of car-following when the density of traffic flow is low and they proposed a better car-following model,

$\ddot{x}_{n, t}=\beta_{E 0} \frac{x_{n, t-\Delta t}}{\left[x_{n-1, t-\Delta t}-x_{n, t-\Delta t}\right]^{2}}\left[\dot{x}_{n-1, t-\Delta t}-\dot{x}_{n, t-\Delta t}\right]$,

where $\beta_{E 0}$ is the sensibility coefficient of drivers in Eide model, and the meanings of other parameters are similar to Eq. (1) and (2).

However, the sensitivity which affects the changes of acceleration/deceleration during car-following is concerned with the changes of acceleration/deceleration of the leading vehicle, which is considered as brake light effect. Besides, the change of acceleration/deceleration is limited by the performance of different vehicles when confronting with the same stimulation. In another words, the max acceleration/deceleration of different vehicles changes significantly due to various performance. For this reason, the extended car-following model considering the performance of different vehicles was proposed as follows,

$$
\begin{aligned}
\ddot{x}_{n, t, l} & =\beta_{0, l} \times\left(x_{n-1, t-\Delta t}-x_{n, t-\Delta t}-L_{n-1}\right)^{\beta_{1, l}} \times \\
& \times\left(\frac{\dot{x}_{n-1, t-\Delta t}}{\dot{x}_{n, t-\Delta t}}\right)^{\beta_{2, l}} \times\left(\frac{\dot{x}_{n-1, t-\Delta t}-\dot{x}_{n, t-\Delta t}}{\mathrm{~d} t}\right)^{\beta_{3, l}},
\end{aligned}
$$

where $\ddot{x}_{n, t, l}$ is the acceleration/deceleration of vehicle $n$ at time $t$ when following, $l$ is the pattern of car-following, which refers to the patterns of car-following-car, carfollowing-bus, bus-following-bus and bus-following-bus, $x_{n-1, t-\Delta t}-x_{n, t-\Delta t}-L_{n-1}$ is the gap between two vehicles in the car-following behaviors, $\frac{\dot{x}_{n-1, t-\Delta t}}{\dot{x}_{n, t-\Delta t}}$ is the velocity ratio between the two vehicles, which describes the response of the acceleration/deceleration of the following vehicle to the stimulation from velocity change of the leading vehicle.

From the definition of the parameters in the formulations, the paper proposed a car-following model 
which is concerned not only with the stimulating intensity giving by the change of driving behaviors in the front vehicle, but also with traffic flow state, vehicle classes, vehicle performance (the performance of acceleration/ deceleration) variation and so on so forth.

\section{Data collection and analysis 3.1 Data collection}

Compared to the other detectors, the traffic flow data, being used to describe the interaction among different vehicles, was obtained by the combination of microwave radar detector and roadside laser detector. The type of microwave radar detector is Patch Antenna type29 of SMARTMICRO Company and the type of roadside laser detector is AxleLight RLU11. The Xuanwu Avenue in the main urban area of Nanjing was selected as the data collecting site. The layout drawing of data collection sites and detectors is shown as follows:

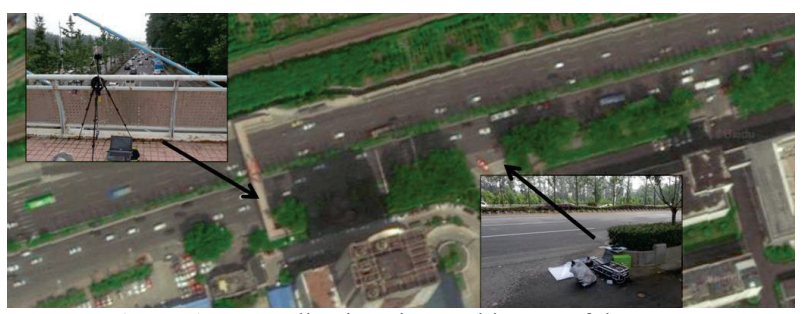

Figure 1 Data collection sites and layout of detectors

\subsection{Analysis of the gap of car-following}

In order to protect driving in car-following conditions, the driving behaviors are probably different when confronting with changing gap between vehicles. At the same time, the minimum gap which drivers want to keep will also be different due to the performance of vehicles in the situation of following. The changes of the gap between vehicles when following according to the data from actual trajectory data are presented in Fig. 2.
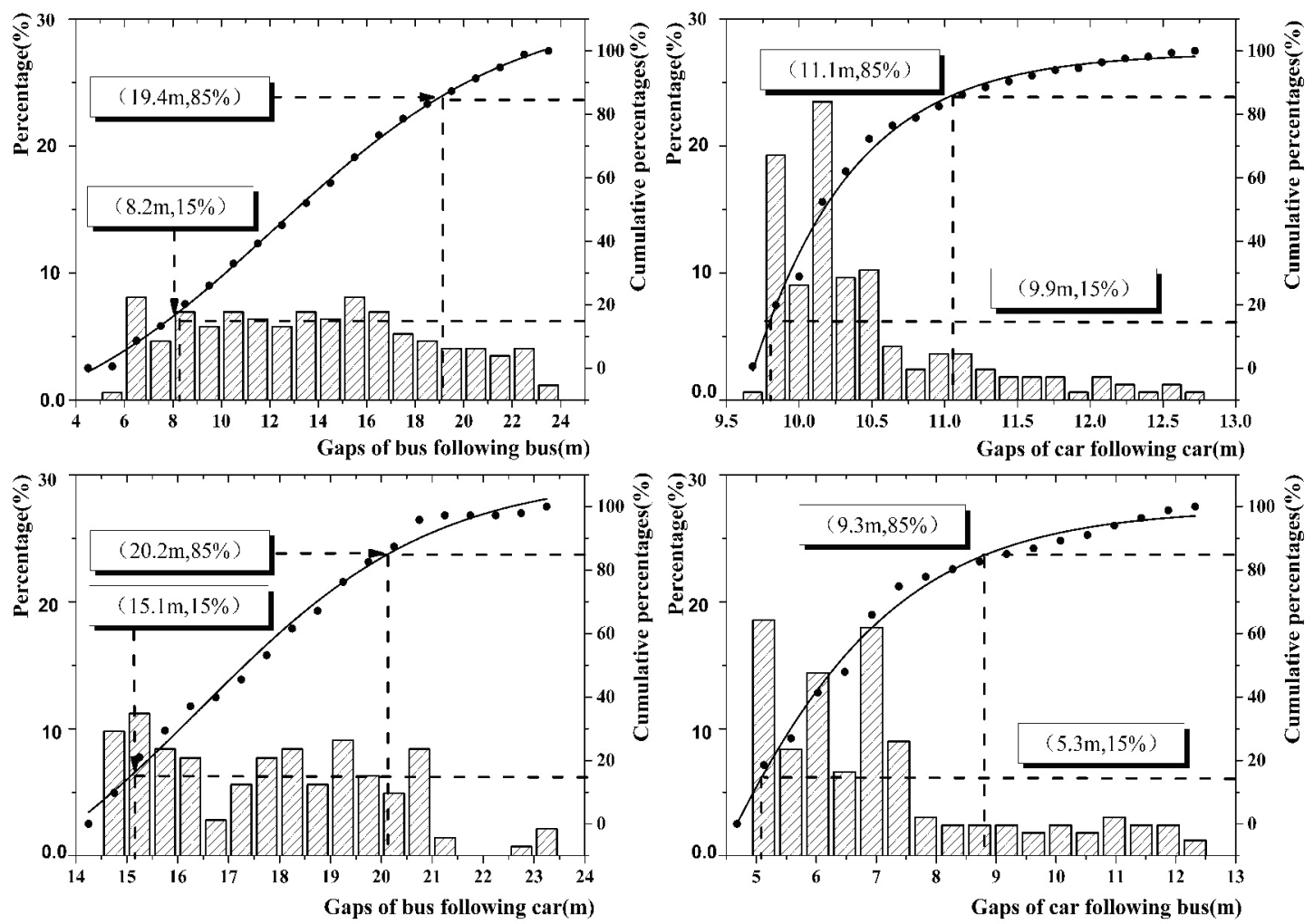

Figure 2 Gaps of different car-following mode

In Fig. 2, the horizontal axis is set to be the gap of car-following in different patterns, and the unit is set to meters. The following behaviors are classified into four patterns with the purpose of investigating their influence, including car-following-car, car-following-bus, busfollowing-bus and bus-following-bus. The vertical axis in the left side, corresponding to the axis of column chat, is set to be the percentages of gaps of different vehicle following. The vertical axis in the right side, corresponding to the axis of cumulative percentages in the scatter diagram and fitted curve, is set to be cumulative percentages of gaps of different vehicle following. The number of vehicles with the gap of following less than 9.9 $\mathrm{m}$ only occupies $15 \%$ of total during car-following-car. Even the gap rises to $11.1 \mathrm{~m}$; they still occupy $15 \%$ of total. When the gap of following is reduced below $5.3 \mathrm{~m}$ or enlarged more than $11.1 \mathrm{~m}$, the number of vehicles occupies $15 \%$ of total during car-following-bus. The specific difference lies in the change of gap of car following for the reason that car changes its speed casually but the bus often maintains a steady speed.

It indicates that the numbers of vehicles with the gap of following less than $8.3 \mathrm{~m}$ or more than $19.4 \mathrm{~m}$, occupies $15 \%$ of total during bus-following-bus. And the numbers of vehicles with the gap of following less than $15.1 \mathrm{~m}$ or more than $20.2 \mathrm{~m}$, both occupy $15 \%$ of total during bus-following-car. The difference of gap of following is the main reason for the uneven distribution of traffic flow on the lanes. In addition to this, it is also the key point resulting in traffic capacity damage. 


\subsection{Analysis of velocity difference of following behaviours}

The velocity difference of following behaviors can be classified into three patterns, including velocity variety of the following car, velocity disparity and the change of acceleration/deceleration. The velocity distributions of the car behind in different car-following patterns are presented in Fig. 3.
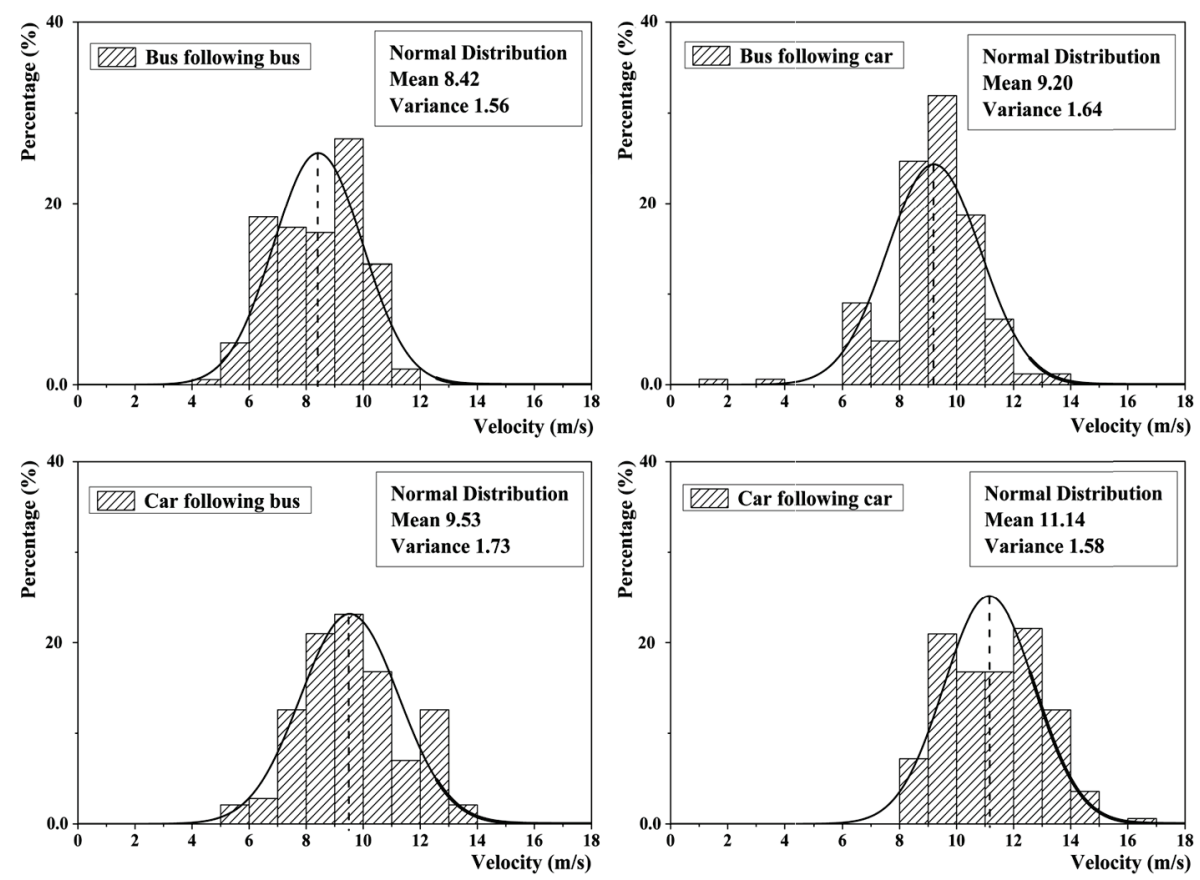

Figure 3 Velocity distribution of following vehicle
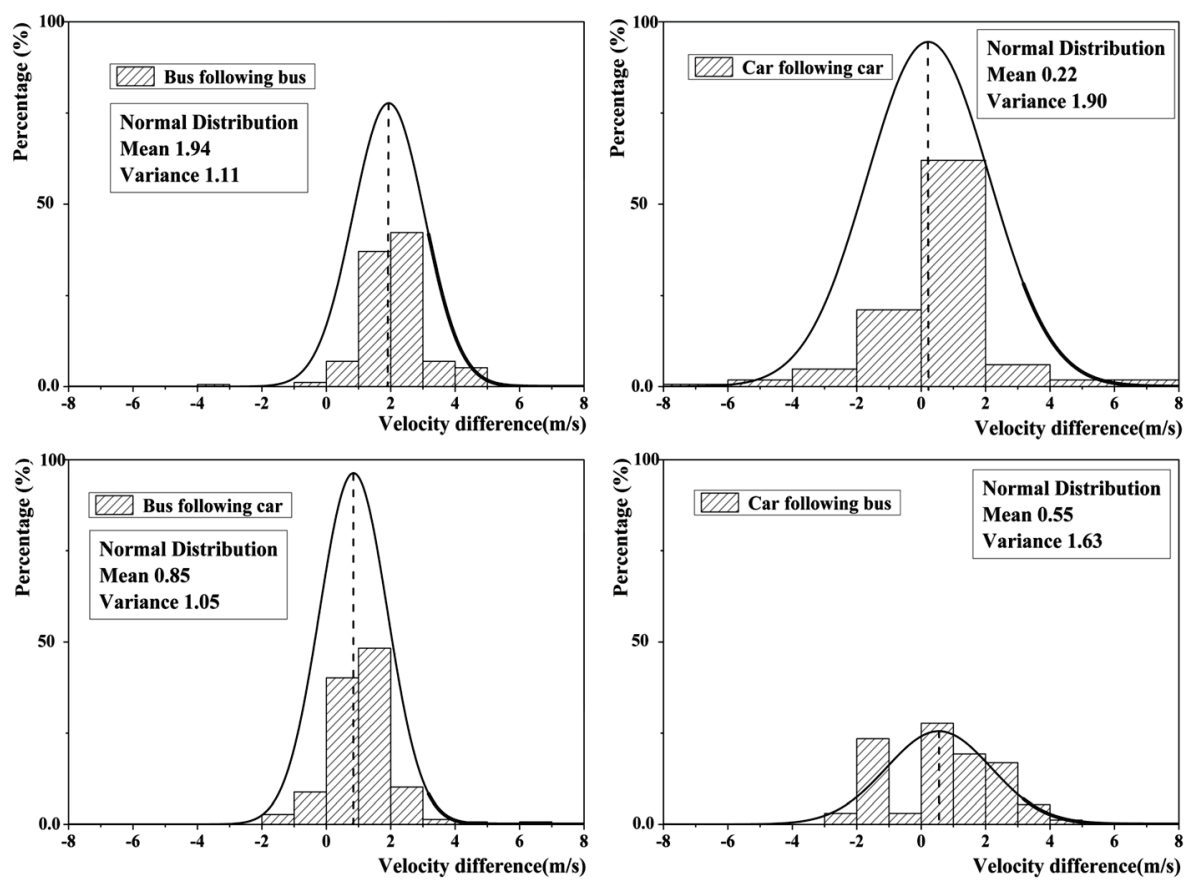

Figure 4 Difference between car and bus speed in car following process

In Fig. 3, the horizontal axis is set to be the following velocity of the car behind with the unit of meters per second, and the vertical axis is set to be the proportion of velocity. The curves in these diagrams are fitted by the distribution function according to the distribution data of columnar component velocity. The velocity differs from the types of vehicles behind during the process of carfollowing. Although the velocity of different vehicles contents a normal distribution, the velocity of busfollowing-bus was measured to be $8.42 \mathrm{~m} / \mathrm{s}$ and the velocity of bus-following-car can reach $9.2 \mathrm{~m} / \mathrm{s}$. The velocity of bus has decreased by eight percent because of the existence of bus-following in the mixed traffic flow. Similarly, the velocity of car also has decreased by fifteen percent for the velocity of car-following-car was measured to be $11.14 \mathrm{~m} / \mathrm{s}$ while the velocity of carfollowing-bus dropped to $9.53 \mathrm{~m} / \mathrm{s}$. It indicates that the velocity distributes unevenly on the lanes because of the merging of public transit. Accordingly, the velocity of many passenger cars is below the velocity of bus. 
Difference distribution between car and bus speed in car following process is shown in Fig. 4.

In Fig. 4, the horizontal axis is set to be the velocity difference between two vehicles with the unit of meters per second, and the vertical axis is set to be the proportion of following vehicles with velocity difference. The distribution curves in these diagrams are fitted by the columnar distribution data of velocity difference. From the figure, the velocity difference between two vehicles confirms to normal distribution. But the distribution is different from the vehicle types. Put simply, passenger cars always have better performance and their drivers are willing to change the velocity and driving lanes for the better experience. So, the velocity difference when following car fluctuates more strongly than the velocity difference when following bus.

The velocity difference of car-following-bus is 0.55 $\mathrm{m} / \mathrm{s}$, which is more than twice as much as the $0.22 \mathrm{~m} / \mathrm{s}$ of the velocity difference of car-following-car. The velocity difference of bus-following-car $1.85 \mathrm{~m} / \mathrm{s}$ is more than three times as much as the velocity difference of busfollowing-bus which is only $0.55 \mathrm{~m} / \mathrm{s}$. The deviation of velocity of different patterns of car-following is considered as the main reasons for the decline of highway capacity. Apart from discussing the changes of velocity during car-following, the paper has selected 120 data sets to study the acceleration changes of the vehicle behind when following. The study result is presented in Fig. 5.
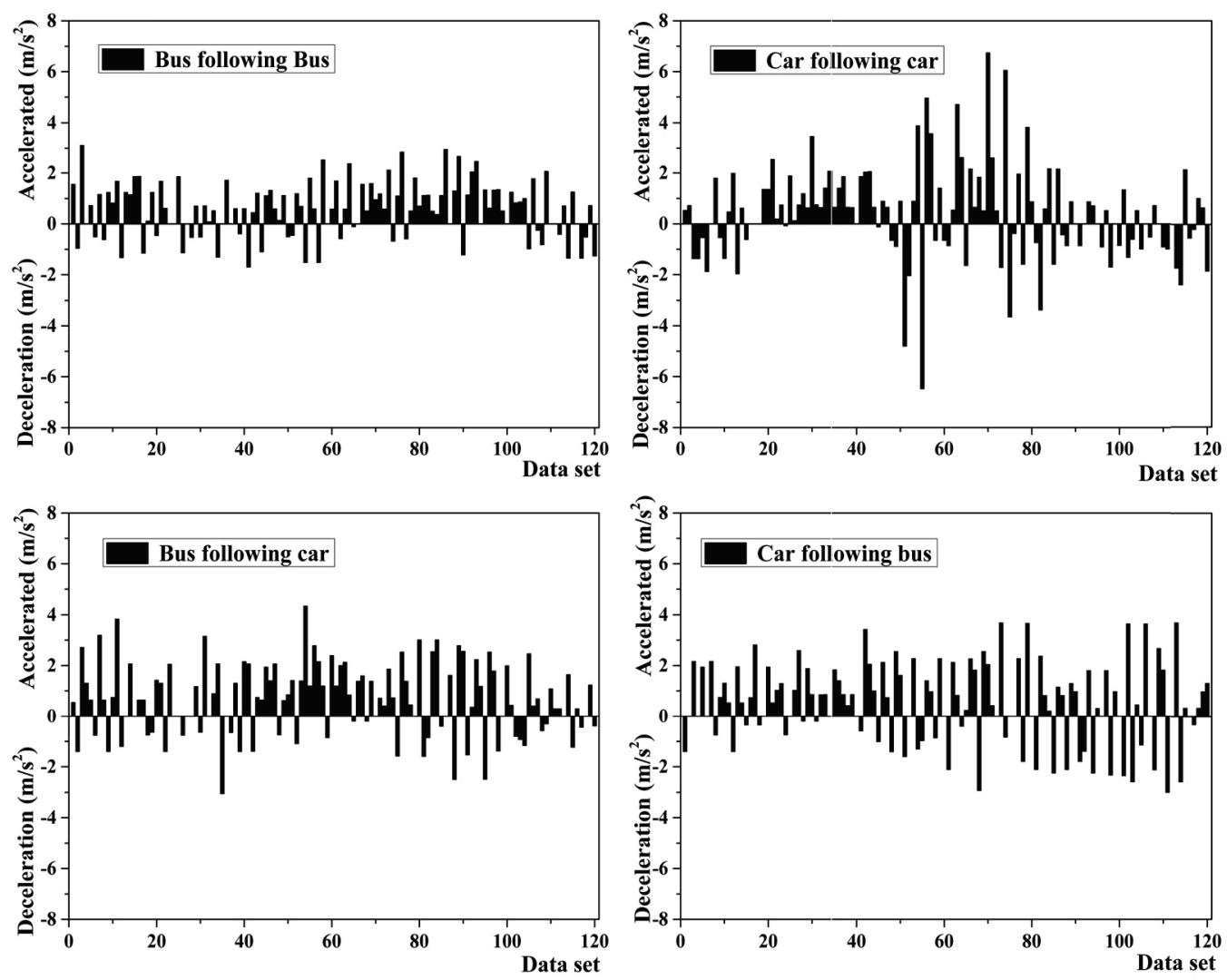

Figure 5 Deceleration and acceleration of following vehicles in car-following process

In Fig. 5, the horizontal axis is set to be the carfollowing data from 120 data sets, and the top side and down side of vertical axis are set to be the acceleration and deceleration of the following vehicle respectively, with the unit of meters per second squared. From the figure, it is apparent that the acceleration/deceleration of the following vehicle changes according to the differences of driving behaviors of the leading vehicle. During carfollowing-car, the acceleration/deceleration of the vehicle behind can reach $6 \mathrm{~m} / \mathrm{s}^{2}$, which is almost the double of the value during car-following-bus.

The acceleration/deceleration of the following vehicle varies within $3 \mathrm{~m} / \mathrm{s}^{2}$ during bus-following-bus. But it can reach $5 \mathrm{~m} / \mathrm{s}^{2}$ during bus-following-car. At this time, the acceleration/deceleration of bus changes greatly due to the leading vehicle is passenger car. Because of the casual driving behaviors of passenger cars, the traffic accidents are more easily caused by frequently heavy acceleration and deceleration of passenger cars when following.

\section{Calibration of model and analysis 4.1 Calibration of model}

When calibrating the model, the field data was classified into two parts in order to study the applicability of the model proposed in this paper and the Gazis and Edie model. The data of each part was divided into eight groups according to acceleration, deceleration and carfollowing patterns (including car-following-car, carfollowing-bus, bus-following-bus and bus-following-car). The analysis was classified into two stages. In the first stage, the nonlinear minimum square regression equation was selected to fit the parameters of three car-following patterns by using the data from the first part. In the second stage, the forecast results would be compared and analyzed by using the data from the second part.

The general car-following equation can be set like Eq. (3) according to the requirement of the minimum square regression equation. 
$f\left(x_{n, t}\right)=f\left(\beta, X_{n, t-\Delta t}\right)+u_{t-\Delta t}, \quad(t=1,2, \ldots, T)$,

where $f\left(x_{n, t}\right)$ is the dependent variable of, $\beta$ is the unknown vector of $k, X_{n, t-\Delta t}$ is the explaining variable at time $t-\Delta t, u_{t-\Delta t}$ is the error term at time $t-\Delta t$, when it follows normal distribution, $E\left(u_{t-\Delta t}\right)=0$ and $\operatorname{Var}\left(u_{t-\Delta t}\right)=\sigma^{2}$, and $T$ is the amount of data during observation.
The 1600 couples of car-following data, selected by the first part, were classified into 8 groups according to acceleration/deceleration and car-following patterns. Each group contains 200 couples which were used for analysis of model parameters calibration. The 800 couples of carfollowing data selected by the second part were used for analyzing the fitting results. Each group contains 100 couples.

The final fitting results through maximum likelihood estimation of the first part data are presented in Tab. 1.

Table 1 Parameters fitting results of the model proposed in this paper

\begin{tabular}{|c|c|c|c|c|c|c|}
\hline \multicolumn{2}{|c|}{ Category } & $\beta_{0}$ & $\beta_{1}$ & $\beta_{2}$ & $\beta_{3}$ & $R^{2}$ \\
\hline \multirow{2}{*}{ Bus-following-bus } & Acceleration & 0.2245 & 0.6511 & 0.5257 & 0.0001 & 0.83 \\
\hline & Deceleration & 0.7418 & -0.1522 & 0.8485 & 0.0003 & 0.72 \\
\hline \multirow{2}{*}{ Car-following-car } & Acceleration & 5.3197 & -1.6116 & 4.8996 & 0 & 0.62 \\
\hline & Deceleration & 30.368 & -1.593 & -0.4587 & -0.1221 & 0.65 \\
\hline \multirow{2}{*}{ Car-following-bus } & Acceleration & 35.357 & -1.3156 & 0.5439 & 0.0003 & 0.84 \\
\hline & Deceleration & 0.0001 & 3.1173 & -0.7944 & -0.1906 & 0.7 \\
\hline \multirow{2}{*}{ Bus-following-car } & Acceleration & 0.1242 & 1.0699 & 0.2817 & 0.0001 & 0.64 \\
\hline & Deceleration & 38.303 & -2.235 & -0.2705 & 0.1222 & 0.89 \\
\hline
\end{tabular}

The table indicates that all the determination coefficients about the judgment of parameters fitting results rise over 0.6. In addition, the determination coefficients of the acceleration of bus-following-bus and car-following-bus and the deceleration of bus-followingcar are over 0.8. The reason for the differences in different car-following patterns is that the velocity of bus when following is more stable than car. Generally speaking, the fitting result of the model proposed in this paper is considered more accurate and reasonable.

The parameters fitting results of Gazis model and Edie model according to the data in the first part are presented in Tab. 2.

Table 2 Parameters fitting results of Gazis and Edie model

\begin{tabular}{|c|c|c|c|c|c|c|c|}
\hline \multicolumn{2}{|c}{ Category } & \multicolumn{3}{c|}{ Gazis model } & \multicolumn{3}{c|}{ Edie model } \\
\cline { 3 - 7 } & & $\beta_{0}$ & $\beta_{1}$ & $\beta_{2}$ & $R^{2}$ & $\beta_{0}$ & $R^{2}$ \\
\hline \multirow{2}{*}{ Bus-following-bus } & Acceleration & 0.19698 & -0.04828 & 0.85394 & 0.53 & 15.235 & 0.42 \\
\cline { 2 - 8 } & Deceleration & 0.31889 & 0.6959 & -0.63353 & 0.33 & 7.8103 & 0.26 \\
\hline \multirow{2}{*}{ Car-following-car } & Acceleration & 0.00015 & 3.6594 & 0.1353 & 0.34 & 10.586 & 0.47 \\
\cline { 2 - 8 } & Deceleration & 100.18 & -1.7941 & -0.33862 & 0.61 & 8.0018 & 0.26 \\
\hline \multirow{2}{*}{ Car-following-bus } & Acceleration & 137.1 & -2.0527 & 0.30553 & 0.31 & 25.986 & 0.32 \\
\cline { 2 - 8 } & Deceleration & -0.83104 & -10.744 & 5.1192 & 0.69 & 21.854 & 0.34 \\
\hline \multirow{2}{*}{ Bus-following-car } & Acceleration & 2.5638 & 0.89093 & -1.1744 & 0.4 & 2.3469 & 0.31 \\
\cline { 2 - 8 } & Deceleration & 51.834 & -3.0664 & 0.4471 & 0.37 & 2.199 & 0.38 \\
\hline
\end{tabular}

From the table, the fitting effect of Gazis model can be preliminarily ascertained better than Edie model.

\subsection{Contrastive analysis of different car-following patterns}

The model proposed in this paper will be compared with the Gazis model and Edie model by the data from second part. The applicability of different models will be mainly investigated and the forecasting results by different measuring methods will be presented in Fig. 6 .

It can be found from Fig. 6 that the accuracy of prediction in the model proposed in this paper is apparently higher than Gazis model and Edie model. And in most cases, the accuracy of prediction in Gazis model is higher than Edie model, which can give a better description of car-following behaviors under the influence of public transit.

To assess the performance among different models with the field data, this paper selects Root Mean Square Error (RMSE), Theil inequality coefficient $(U)$, Mean Absolute Error $(M A E)$, Mean Absolute Percentage Error
$(M A P E)$, and Variance of Absolute Percentage Error $(V A P E)$ as evaluation indicators.

Root mean square Error (RMSE) measures the deviations between the estimated and field observed values, and is defined by Eq. (4).

$R M S E=\sqrt{\frac{1}{T} \sum_{t=1}^{T}\left(\frac{y_{t}^{0}-y_{t}^{c}}{y_{t}^{0}}\right)^{2}}$

Theil inequality coefficient $(U)$ measures the scaled root mean squared difference between the estimated and field observed values, and is defined by Eq. (5).

$$
U=\frac{\sqrt{\frac{1}{T} \sum_{t=1}^{T}\left(y_{t}^{0}-y_{t}^{c}\right)^{2}}}{\sqrt{\frac{1}{T} \sum_{t=1}^{T}\left(y_{t}^{c}\right)^{2}}+\sqrt{\frac{1}{T} \sum_{t=1}^{T}\left(y_{t}^{0}\right)^{2}}}
$$


Mean absolute error $(M A E)$ is a quantity used to measure how close forecasts or predictions are to the eventual outcomes, and is defined by Eq. (6).

$$
M A E=\frac{\sum_{t=1}^{N}\left|y_{t}^{0}-y_{t}^{c}\right|}{N}
$$

Mean absolute percentage error $(M A P E)$ is a measure of prediction accuracy of a forecasting method in statistics. It usually expresses accuracy as a percentage, and is defined by Eq. (7).

$$
M A P E=\frac{1}{N} \sum_{t=1}^{N} \frac{\left|y_{t}^{0}-y_{t}^{c}\right|}{y_{t}^{0}}
$$
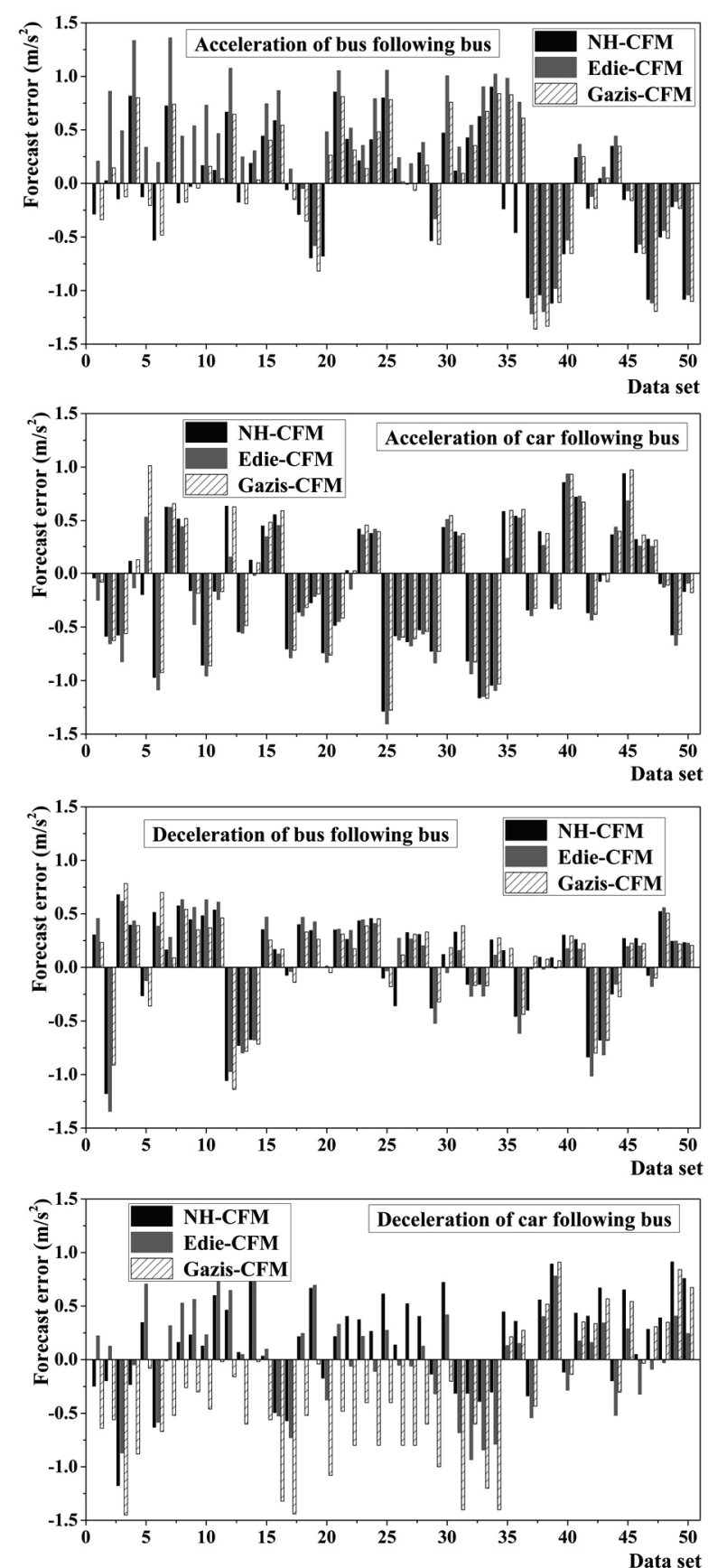

The variance of absolute percentage error $(V A P E)$ is a variance of prediction accuracy of a forecasting method in statistics. It usually expresses how far a set of (random) numbers is spread out from their mean, and is defined by Eq. (8).

$V A P E=\operatorname{Var}\left(\frac{\left|y_{t}^{0}-y_{t}^{c}\right|}{y_{t}^{0}}\right) \times 100 \%$

where $T$ is car-following data groups from observation, $y_{t}^{c}$ is the acceleration/deceleration value of prediction from the model, $y_{t}^{0}$ is the acceleration data from observation.
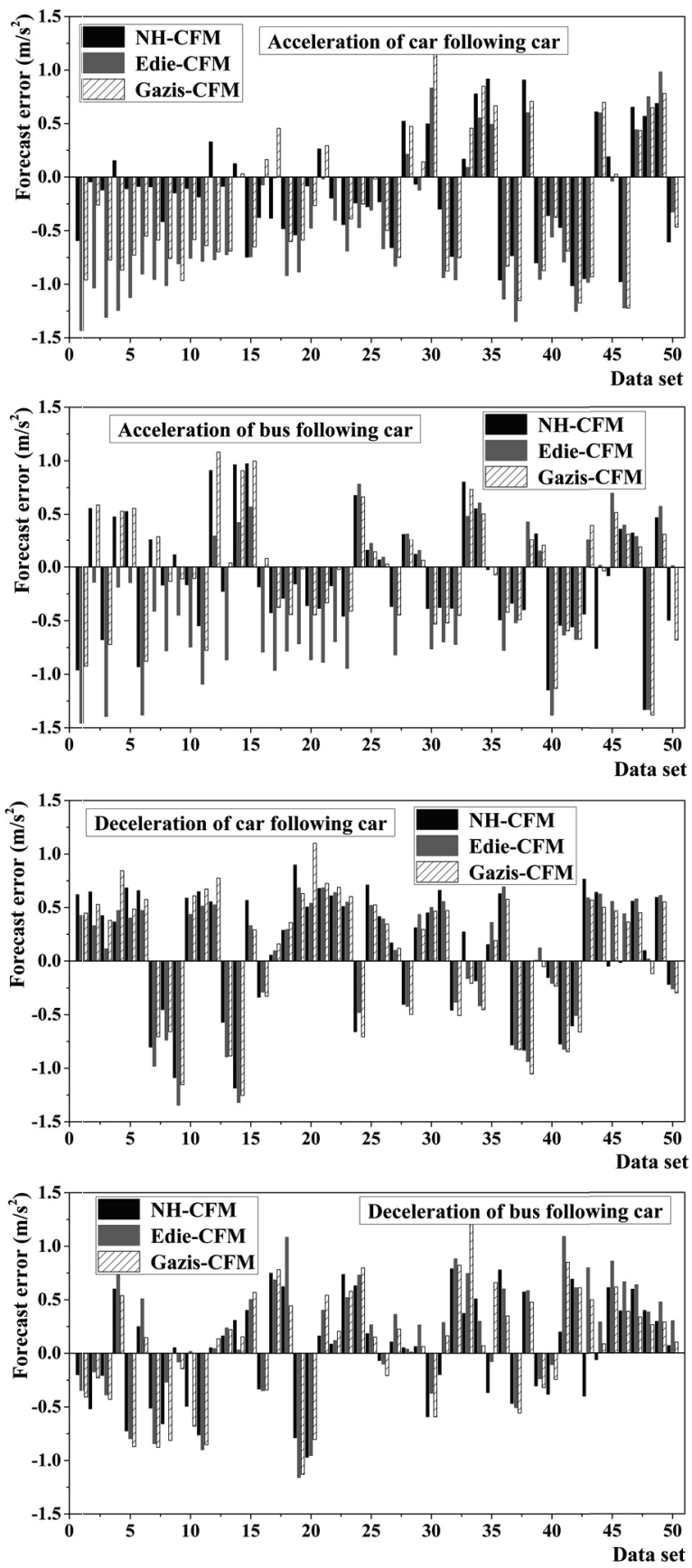

Figure 6 Prediction results of different car-following models 
The final analysis results of different patterns are illustrated in Tab. 3 according to the prediction of each model by the data from the second part.

It can be found from Tab. 3 that the model proposed in this paper is more stable than Gazis model and Edie model when predicting the acceleration/deceleration during car-following. Compared to the prediction result of Edie model, Gazis model has more stability and reliability in most cases. However, Edie model is more reliable when predicting the acceleration of car-following-car and bus-following-car, and deceleration of bus-following-bus and car-following-car.

Table 3 Evaluation of different models

\begin{tabular}{|c|c|c|c|c|c|c|c|}
\hline \multirow{2}{*}{\multicolumn{3}{|c|}{ Category }} & \multicolumn{5}{|c|}{ Evaluation indictor } \\
\hline & & & $M A E$ & $M A P E$ & $V A P E$ & RMSE & $U$ \\
\hline \multirow{12}{*}{ Acceleration } & \multirow{3}{*}{ Bus-following-bus } & This study model & 0.53 & 1.07 & 3.35 & 2.1 & 0.41 \\
\hline & & Edie model & 0.68 & 1.62 & 7.01 & 3.08 & 0.33 \\
\hline & & Gazis model & 0.54 & 1.12 & 3.5 & 2.16 & 0.33 \\
\hline & \multirow{3}{*}{ Car-following-car } & This study model & 0.76 & 0.80 & 1.94 & 1.59 & 0.54 \\
\hline & & Edie model & 1.04 & 0.97 & 3.12 & 2 & 0.42 \\
\hline & & Gazis model & 0.92 & 0.92 & 2.25 & 1.74 & 0.44 \\
\hline & \multirow{3}{*}{ Car-following-bus } & This study model & 0.47 & 0.70 & 1.27 & 1.18 & 0.38 \\
\hline & & Edie model & 0.58 & 0.79 & 1.53 & 1.46 & 0.32 \\
\hline & & Gazis model & 0.59 & 0.90 & 1.98 & 1.66 & 0.31 \\
\hline & \multirow{3}{*}{ Bus-following-car } & This study model & 0.43 & 1.17 & 4.08 & 1.78 & 0.51 \\
\hline & & Edie model & 0.69 & 1.45 & 6.32 & 2.88 & 0.47 \\
\hline & & Gazis model & 0.51 & 1.79 & 18.67 & 4.64 & 0.31 \\
\hline \multirow{12}{*}{ Deceleration } & \multirow{3}{*}{ Bus-following-bus } & This study model & 0.33 & 1.18 & 15.16 & 3.42 & 0.52 \\
\hline & & Edie model & 0.43 & 2.37 & 37.44 & 6.51 & 0.43 \\
\hline & & Gazis model & 0.41 & 1.90 & 17.19 & 4.52 & 0.41 \\
\hline & \multirow{3}{*}{ Car-following-car } & This study model & 0.53 & 1.73 & 5.93 & 3.06 & 0.56 \\
\hline & & Edie model & 0.64 & 2.11 & 6.2 & 3.24 & 0.49 \\
\hline & & Gazis model & 0.67 & 2.42 & 9.08 & 3.84 & 0.48 \\
\hline & \multirow{3}{*}{ Car-following-bus } & This study model & 0.35 & 1.53 & 2.08 & 0.95 & 0.69 \\
\hline & & Edie model & 0.44 & 2.57 & 58.12 & 7.97 & 0.34 \\
\hline & & Gazis model & 0.67 & 1.90 & 4.22 & 2.02 & 0.53 \\
\hline & \multirow{3}{*}{ Bus-following-car } & This study model & 0.42 & 1.75 & 22.1 & 4.91 & 0.43 \\
\hline & & Edie model & 0.52 & 2.18 & 40.05 & 6.63 & 0.35 \\
\hline & & Gazis model & 0.50 & 1.98 & 35.27 & 6.2 & 0.35 \\
\hline
\end{tabular}

\section{Research conclusions}

In this paper, compared to the existing study of carfollowing models, an extended car-following model has been proposed considering the influence of public transit on the expressway. The study results obtained from the influence of space headway on car-following behaviors indicates that the differences of space headway in different car-following patterns lead to uneven distribution of traffic flow on the lanes and become the main reason for highway capacity decline. Besides, the research about the difference of velocity in the four carfollowing patterns shows the variation of the acceleration/deceleration of the following vehicle is due to the driving behaviors of the leading vehicle. On the basis of measured data analysis, the non-linear least square regression is selected to fit the parameters of the model proposed in this paper. In order to analyze the applicability of the model, it was compared to Edie model and Gazis model, in which the prediction of acceleration/deceleration during car-following is the main target to the research. The prediction results obtained by different measure methods have proved that our model gives a better description of the car-following behaviors on the expressway under the influence of public transit.

\section{Acknowledgments}

This work is supported by Key Laboratory of Integrated Regulation and Resources Development on
Shallow Lake of Ministry of Education (Grant No. 2015B06114), Jiangsu Planned Projects for Postdoctoral Research Funds (Grant No. 1701086B), Natural Science Foundation of Jiangsu Province (Grant No. BK20170879), and the Fundamental Research Funds for the Central Universities (Grant No. 2016B01014).

\section{References}

[1] Brackstone, M.; McDonald, M. Car-following: a historical review. // Transportation Research Part F: Traffic Psychology and Behaviour. 2, 4(1999), pp. 181-196. https://doi.org/10.1016/S1369-8478(00)00005-X

[2] Jurecki, R.; Poliak, M.; Jaśkiewicz, M. Young Adult Drivers: Simulated Behaviour in a Car-following Situation. // Promet - Traffic \&Transportation. 29, 4(2017), pp. 381390. https://doi.org/10.7307/ptt.v29i4.2305

[3] Pipes, L. A. An Operational Analysis of Traffic Dynamics. // Journal of Applied Physics. 24, 3(1953), pp. 274. https://doi.org/10.1063/1.1721265

[4] Chandler, R. E.; Herman, R.; Montroll, E. W. Traffic Dynamics: Studies in Car Following. // Operations Research. 6, 2(1958), pp. 165-184. https://doi.org/10.1287/opre.6.2.165

[5] Gazis, D. C.; Herman, R.; Potts, R. B. Car-Following Theory of Steady-State Traffic Flow. // Operations Research. 7, 4(1959), pp. 499-505. https://doi.org/10.1287/opre.7.4.499

[6] Edie, L. C. Car-Following and Steady-State Theory for Noncongested Traffic. // Operations Research. 9, 1(1961), pp. 66-76. https://doi.org/10.1287/opre.9.1.66 
[7] Sheu, J. Characterisation of driver behaviour during car following using quantum optical flow theory. // Transportmetrica A - Transport Science. 9, 3(2013), pp. 269-298. https://doi.org/10.1080/18128602.2011.572571

[8] Yu, S.; Liu, Q.; Li, X. Full velocity difference and acceleration model for a car-following theory. // Communications in Nonlinear Science and Numerical Simulation. 18, 5(2013), pp. 1229-1234. https://doi.org/10.1016/j.cnsns.2012.09.014

[9] Liu, R.; Li, X. Stability analysis of a multi-phase carfollowing model. // Physica A: Statistical Mechanics and its Applications. 392, 11(2013), pp. 2660-2671. https://doi.org/10.1016/j.physa.2013.02.001

[10] Tang, T.; He, J.; Yang, S. et al. A car-following model accounting for the driver's attribution. // Physica A: Statistical Mechanics and its Applications. 413(2014), pp. 583-591. https://doi.org/10.1016/j.physa.2014.07.035

[11] Tang, T.; Shi, W.; Shang, H. et al. An extended carfollowing model with consideration of the reliability of inter-vehicle communication. // Measurement. 58(2014), pp. 286-293. https://doi.org/10.1016/j.measurement.2014.08.051

[12] Yu, L.; Shi, Z.; Li, T. A new car-following model with two delays. // Physics Letters A. 378, 4(2014), pp. 348-357. https://doi.org/10.1016/j.physleta.2013.11.030

[13] Zhu, W.; Zhang, L. A speed feedback control strategy for car-following model. // Physica A: Statistical Mechanics and its Applications. 413(2014), pp. 343-351. https://doi.org/10.1016/j.physa.2014.07.030

[14] Zheng, Y.; Zheng, P.; Ge, H. An improved car-following model with consideration of the lateral effect and its feedback control research. // Chinese Physics B. 23, 2(2014), pp. 1-5. https://doi.org/10.1088/1674-1056/23/2/020503

[15] Saifuzzaman, M.; Haque, M. M.; Zheng, Z. et al. Impact of mobile phone use on car-following behaviour of young drivers. // Accident Analysis \& Prevention. 82(2015), pp. 10-19. https://doi.org/10.1016/j.aap.2015.05.001

[16] Davoodi, N.; Soheili, A. R.; Hashemi, S. M. A macromodel for traffic flow with consideration of driver's reaction time and distance. // Nonlinear Dynamics. 83, 3(2016), pp. 1621-1628. https://doi.org/10.1007/s11071-015-2435-0

[17] Ossen, S.; Hoogendoorn, S. P. Heterogeneity in carfollowing behavior: Theory and empirics. // Transportation Research Part C: Emerging Technologies. 19, 2(2011), pp. 182-195. https://doi.org/10.1016/j.trc.2010.05.006

[18] Ravishankar, K. V. R.; Mathew, T. V. Vehicle-Type Dependent Car-Following Model for Heterogeneous Traffic Conditions. // Journal of Transportation Engineering. 137, 11(2011), pp. 775-781. https://doi.org/10.1061/(ASCE)TE.1943-5436.0000273

[19] Aghabayk, K.; Sarvi, M.; Young, W. Understanding the Dynamics of Heavy Vehicle Interactions in Car-Following. // Journal of Transportation Engineering.138, 12(2012), pp. 1468-1475. https://doi.org/10.1061/(ASCE)TE.1943-5436.0000463

[20] Sarvi, M. Heavy commercial vehicles-following behavior and interactions with different vehicle classes. // Journal of Advanced Transportation. 47, 6(2013), pp. 572-580.

[21] Aghabayk, K.; Sarvi, M.; Forouzideh, N. et al. Modelling heavy vehicle car-following behaviour in congested traffic conditions. // Journal of Advanced Transportation. 48, 8(2014), pp. 1017-1029. https://doi.org/10.1002/atr.1242

[22] Yang, D.; Qiu, X.; Yu, D. et al. A cellular automata model for car-truck heterogeneous traffic flow considering the car-truck following combination effect. // Physica A: Statistical Mechanics and its Applications. 424(2015), pp. 62-72. https://doi.org/10.1016/j.physa.2014.12.020
[23] Yang D, Zhu L, Pu Y. Model and Stability of the Traffic Flow Consisting of Heterogeneous Drivers. // Journal of Computational and Nonlinear Dynamics, 10(2015), pp.0310011-03100110. https://doi.org/10.1115/1.4025896

[24] Li Z, Li W, Xu S, et al. Traffic behavior of mixed traffic flow with two kinds of different self-stabilizing control vehicles. //Physica A: Statistical Mechanics and its Applications, 436(2015), pp. 729-738. https://doi.org/10.1016/j.physa.2015.05.090

[25] Liu L, Zhu L, Yang D. Modeling and simulation of the cartruck heterogeneous traffic flow based on a nonlinear carfollowing model. // Applied Mathematics and Computation, 273(2016), pp. 706-717.

https://doi.org/10.1016/j.amc.2015.10.032

\section{Authors' addresses}

\section{Jinxing Shen, Dr. Lecturer}

(Corresponding author)

1. Key Laboratory of Integrated Regulation and Resource Development on Shallow Lake of Ministry of Education, College of Environment,

2. College of Civil and Transportation Engineering,

Hohai University,

Xi Kang Road 1\#, Nanjing, 210098, China

E-mail: shenjx03@163.com

Feng Qiu, Dr.

Department of Computer Science,

University of Victoria,

3800 Finnerty Rd, Victoria, BC V8P 5C2, Canada

E-mail: qfyouxiang@hotmail.com

Rui Li, Associate Professor Dr.

College of Civil and Transportation Engineering,

Hohai University,

Xi Kang Road 1\#, Nanjing, 210098, China

E-mail: lirui2012@hhu.edu.cn

Changjiang Zheng, Professor Dr.

College of Civil and Transportation Engineering, Hohai University,

Xi Kang Road 1\#, Nanjing, 210098, China

E-mail: zhenghhu@sina.com 